(C)2008 IEEE. Personal use of this material is permitted. However, permission to reprint/republish this material for advertising or promotional purposes or for creating new collective works for resale or redistribution to servers or lists, or to reuse any copyrighted component of this work in other works must be obtained from the IEEE. 


\title{
Economic Assessment of Transmission Expansion Projects in Competitive Electricity Markets - An Analytical Review
}

\author{
M. R. Hesamzadeh, Graduate Student Member, IEEE, N. Hosseinzadeh, Member, IEEE, and \\ P. J. Wolfs, Senior Member IEEE
}

\begin{abstract}
Restructuring of the electricity market has changed many aspects of the transmission system operation and planning. Reliability-Driven and Economic-Driven transmission expansion planning by regulated and private utilities are the substitutes of the traditional Cost-Driven transmission expansion planning. Reliability-based criteria for assessment of the transmission projects are almost well-developed while there exists a lack of a comprehensive framework for the economic evaluation of the transmission projects.
\end{abstract}

Definition of a quantitative and monetary framework for economic evaluation of future transmission projects demands a detailed market analysis. In addition, specific characteristics and responsibilities of the transmission system in the open access structure must be understood comprehensively. To reaching the aforementioned goal, an analytical review on the existing economic assessment methodologies would be highly beneficial for the researchers in this area.

Moreover, most of the review literatures on transmission investment in competitive electricity markets are general. These review literatures have tried to address all aspects of this challenging issue with devoting only few paragraphs to economic assessment of transmission projects.

Given the aforementioned shortcomings, this article would bridge the gap by the following contributions: Firstly, reviewing available approaches for economic assessment of transmission projects based on research papers and industrial reports ,Secondly, analysing the reviewed criteria critically by applying them to a modified Wood and Wollenberg 6-bus case study and Finally, summarizing the key components of a successful Economic Assessment Framework for transmission expansion or upgrade projects.

Practical experiences of California Electricity Market, New England Electricity Market, Pennsylvania, New Jersey, and Maryland (PJM) and National Electricity Market, Australia have been accommodated in the article.

Index Terms-Economic Assessment, Transmission Expansion, Analytical Review

\section{INTRODUCTION}

Before deregulation has been introduced to the electricity industry in 1990s, the power system had experienced a long monopoly and deterministic environment. In vertically integrated power systems network expansion was intended to meet the present and future system reliability at the minimum cost. By restructuring of the electricity market and over the past decade, issues of electricity market liberalization have been investigated from different perspectives [30]. In parallel with this evolution in the electricity industry, the expansion planning objectives of the transmission system have changed. In this context, the new objectives could be categorized as three groups, namely, (i) to maintain system reliability standards (ii) to keep the environmental impacts of expansions at the proper level and (iii) to improve the economic performance of electricity market.

Reliability indices are not new for transmission planners. Transmission planners have experienced well developed indices in the traditional expansion planning of the transmission systems. Main researches in this area have been focused on the extension of traditional reliability indices. Probabilistic reliability assessment [11] and value based reliability studies [12] are some typical extensions of the reliability indices addressing the new environment of electricity industries.

Under the Kyoto Protocol of 1997, nations would commit to reduce their greenhouse gas emissions to at least 5\% below 1990 base line levels by the year 2012 .

As a result, the burden is increased on transmission planner to have accurate studies on the environmental impacts of the future transmission development. A few approaches are discussed with mixed successes in some and failures in others. Integrating of the environmental impacts in the planning methodology is an emerging issue, which does not have received the appropriate attention until now.

With the guidelines of Federal Energy Regulatory Commission (FERC) of the US on Standard Market Design (SMD) [5] and the recent reviewing of Council of Australian Government (COAG) on the design and implementation of electricity restructuring in Australia [3], the definition and development of metrics for measuring the performance of the electricity market has emerged as a contemporary issue.

On the other hand, transmission system planners would use these performance metrics in their studies to improve the electricity market performance by the effective design of transmission system.

Moreover, most of the literature surveys on transmission planning in deregulated electric systems are general and try to review[23], [25], [26], [27], [28], [29],[30] all the aspects of this multi dimensional problem. Considering existent and emerging issues in the expansion planning of transmission system, the necessity for more specific surveys are highly demanded. This article bridges the gap and reviews different 
alternatives for the economic assessment of the electricity market form the view point of transmission expansion projects.

Reviewed metrics are grouped into main and ancillary measures and have been analysed by applying them to a common 6-bus test system. Based on the analytical review, the necessary ingredients of a successful module in the economic assessment of transmission projects using the main and ancillary measures have been extracted and summarised.

The organization of this paper excluding the introduction part is as follows; the mathematical formulation of the electricity market used for analysis has been given in section II, Section III gives a detailed overview on performance metrics of electricity market in the transmission investment problem. An analysis of the reviewed indices using a typical 6-bus transmission system and the extracted framework for economic assessment of transmission projects are presented through section IV. Finally, the conclusion remarks in section $\mathrm{V}$ will close this paper.

\section{Mathematical Formulation OF THE EleCtRicity MARKET}

Under competition, the well-know social welfare optimization problem is the background of the most economic measures of transmission investment projects. Without loss of generality, the linear version of the social welfare optimisation problem has been adopted for mathematical presentation of reviewed indices [13],[14],[15].

The mathematical formulation of the social welfare optimisation problem can be;

$$
\operatorname{Min} \sum_{\mathrm{i}=1}^{\mathrm{NG}} \widetilde{\mathrm{C}}_{\mathrm{i}}\left(\mathrm{P}_{\mathrm{gi}}\right)-\sum_{\mathrm{j}=1}^{\mathrm{ND}} \widetilde{\mathrm{B}}_{\mathrm{j}}\left(\mathrm{P}_{\mathrm{dj}}\right)
$$

Subject to the supply-load balance equation, quality of transmission network, and system inequality constraints,

$$
\begin{aligned}
& \hat{B}_{x} \vec{\theta}=\vec{P}_{g}-\vec{P}_{d} \Leftrightarrow \vec{\lambda} \\
& -\vec{F}_{l} \leq \hat{H}_{l} \vec{\theta} \leq \vec{F}_{l} \Leftrightarrow \vec{\mu} \\
& \vec{P}_{g}^{\min } \leq \vec{P}_{g} \leq \vec{P}_{g}^{\max } \\
& \vec{P}_{d}^{\min } \leq \vec{P}_{d} \leq \vec{P}_{d}^{\max }
\end{aligned}
$$

In equations (1) through (5),

$N G$ : total number of generators in the transmission network,

$\widetilde{C}_{i}$ : the apparent cost function of generator i in $\$ / \mathrm{hr}$,

$P_{g i}$ : the output generation of the generator i in MW,

$N D$ : total number of price sensitive loads,

$\widetilde{B}_{j}$ : apparent benefit function of dispatchable load j in $\$ / \mathrm{hr}$,

$P_{d j}$ : the dispatched load of sensitive load $\mathrm{j}$ in $\mathrm{MW}$,

$\hat{B}_{x}$ : suseptance matrix of transmission network in mho.,

$\vec{\delta}$ : vector of the node angles in radian,
$\hat{H}_{l}$ : branch node matrix of transmission network in mho,

$\vec{F}_{l}$ : vector of maximum flows of lines in MW,

$\vec{P}_{g}^{\text {min }}$ : vector of minimum generation capacity in MW,

$\vec{P}_{g}^{\max }$ : vector of maximum generation capacity in MW,

$\vec{P}_{d}^{\min }$ : vector of minimum demand in MW,

$\vec{P}_{d}^{\max }$ : vector of maximum demand in MW,

$\vec{\lambda}$ : vector of nodal prices in $\$ / M W h$

$\vec{\mu}$ : vector of the shadow prices of flow limits in $\$ / M W h$

Section III gives a detailed review of economic measures of transmission expansion or upgrade projects.

\section{ECONOMIC PERFORMANCE METRICS IN THE TRANSMISSION INVESTMENT PROBLEM - A REVIEW}

For this review, the article has attempted to narrow down the list and focus on the most comprehensive metrics used in the related literatures. An exact definition along with its mathematical formulation has been provided for each introduced metric.

\section{A. Social Welfare or Aggregated Surplus (TS ) [31], [32],[34]}

The participants of the electricity market are (1) consumers, $\mathrm{C}$, (2) producers, $\mathrm{P}$, and (3) transmission network owners or congestion revenue right holders, CRRH. Hence, the social welfare is the aggregated values of market participants' benefits.

Producers' benefit or surplus (PS) can be defined as the difference between the aggregated revenue and apparent cost of all suppliers. Mathematically speaking,

$$
\begin{aligned}
& P S=\sum_{i=1}^{N G} \lambda_{i} P_{g i}-\widetilde{C}_{i}\left(P_{g i}\right) \\
& C S=-\sum_{j=1}^{N D} \lambda_{j} P_{d j}-\widetilde{B}_{j}\left(P_{d j}\right) \\
& C R=\sum_{j=1}^{N D} \lambda_{j} P_{d j}-\sum_{i=1}^{N G} \lambda_{i} P_{g i}=\sum_{k=1}^{N B} \mu_{k} P_{k}
\end{aligned}
$$

The total surplus is defined as the aggregated value of participants' surpluses;

$$
T S=P S+C S+C R
$$

Based on (9), benefit of transmission expansion or upgrade project can be evaluated as (10).

$$
\Delta T S=\left.T S\right|_{w}-\left.T S\right|_{w / o}
$$

Where, TS $\left.\right|_{w}$ is the Total Surplus with transmission expansion or upgrade and $\left.T S\right|_{w / o}$ is the Total Surplus without transmission expansion or upgrade project. In this formulation, the expansion or upgrade project which has the highest 
positive change in the Total Surplus would be preferable.

\section{B. Electricity Market Efficiency Loss or Congestion Cost [31][32][33]}

Efficiency loss of the electricity market is defined as decrease in social welfare due to transmission network constraints. Mathematically speaking,

$$
E L=T S^{\prime}-T S
$$

Where, $E L$ is the efficiency loss, $T S^{\prime}$ is the total surplus without transmission constraints, and TS is the total surplus of the system.

$$
\Delta E L=-\left(\left.E L\right|_{w}-\left.E L\right|_{w / o}\right)
$$

In this measure, the expansion or upgrade projects which have highest positive change would be selected.

\section{Congestion Rents or Congestion Revenue [31][32] [33]}

Congestion rent or revenue is defined as the money collected by the system operator because of congestion in transmission network. Mathematically speaking, it can be formulated as the equation (8). Congestion revenue as the third component of the total surplus can be understood as the congestion revenue right holders' income who might be producers, consumers, or merchant transmission owners.

\section{Individual Producer Surplus [31][32][33]}

Individual producer surplus is defined as (13).

$P S_{i}=\lambda_{i} P_{g i}-\widetilde{C}_{i}\left(P_{g i}\right)$

Individual producer surplus is the difference between producer revenue and producer cost.

\section{E. Individual Consumer Surplus [31][32][33]}

The difference between individual consumer willingness to pay and consumer paying is called individual consumer surplus. Mathematically speaking,

$$
C S_{j}=\widetilde{B}_{j}\left(P_{d j}\right)-\lambda_{j} P_{d j}
$$

\section{F. Nodal Producer Surplus [31][32][33]}

Nodal producer surplus is defined as the summation of the surpluses of all producers connected to one bus.

$P S_{N_{x}}=\sum_{i=1}^{N G_{N_{x}}} \lambda_{i} P_{g i}-\widetilde{C}_{i}\left(P_{g i}\right)$

Where $N_{x}$ is Node $\mathrm{x}$ of system, and $N G_{N_{x}}$ is the total number of generators connected to node $\mathrm{x}$.

\section{G. Nodal Consumer Surplus [31][32] [33]}

Summation of the surpluses of all consumers connected to one bus is defined as nodal consumer surplus.

$$
C S_{N_{x}}=-\sum_{j=1}^{N D_{N_{x}}} \lambda_{j} P_{d j}-\widetilde{B}_{j}\left(P_{d j}\right)
$$

Where $N_{x}$ is Node $\mathrm{x}$ of system, and $N D_{N_{x}}$ is the total number of demands connected to node $\mathrm{x}$.

\section{H. Producers' Surplus [31][32][33]}

Difference between what the producers collects from the system and the real costs of production is called producers' surplus. Equation (6) is the mathematical definition of this index.

\section{Consumers' Surplus [31][32][33]}

Difference between the demand bids and the demand payments is consumers' surplus. Equation (7) is the mathematical definition of this index.

\section{J. Redispatch Power [31][32][33]}

The redispatched power is defined by the increase, if any, of sellers' productions caused by transmission constraints.

$$
\Delta_{p}=\sum_{i=1}^{N G}\left(P_{g i}-P^{*}{ }_{g i}\right) I \ldots
$$

Where, $P_{g i}^{*}$ is the generation of the $i^{\text {th }}$ generator without transmission constraints, and $P_{g i}$ is the generation with transmission constraints. $I$ is an integer with the following definition;

$$
I=\left\{\begin{array}{cc}
0 & P_{g i}<P^{*}{ }_{g i} \\
1 & P_{g i} \geq P^{*}{ }_{g i}
\end{array}\right.
$$

\section{K. Redispatch Cost [31][32][33]}

The redispatched cost is defined as the difference between the costs of the energy considering transmission constraints and the cost of providing the same energy without transmission constraints.

\section{Load Payment Costs [31][32][33]}

Difference in demand payments with and without congestion is load payment costs.

\section{Total Congestion Cost-Definition [1]}

This paper proposes a methodology to promote fair competition for short term transmission planning by using assessment of transmission line congestion cost index.

The proposed network congestion assessment method is describes as follows. First, given the bidding power of every bus determined in the network, the line power flow can be determined by using the load flow without considering transmission congestion. Next, when there is a line congestion, operation power in each bus is redispatched in order to eliminate the line congestion. The redispatched power at a bus is under/over than the bidding power determined in the market and leads to an extra cost. The total economic cost resulting from the congestion can be quantified from the bidding power and operation power in each bus. 
The bidding power and power price rate at bus $\mathrm{k}$ are $\mathrm{P}_{\mathrm{bk}}$ and $R_{b}$, respectively. The bidding power price rate is common to all busses, since the price rate is assumed to be determined at the equilibrium point of supply and demand in the market. If there is a congestion, power is redispatched to eliminate the congestion. Redispatched operation power and power price rate are $P_{o k}$ and $R_{o k}$, respectively. Now, the operation power price rates are different for each generator bus because the incremental cost curve (ICC) of each plant is different.

If there is a line in which the line flow exceeds the line capacity, then the line has congestion. For single line congestion, congestion cost index (CCI) for bus $\mathrm{k}$ can be calculated as

$C C I_{k}=\left|R_{o k} P_{o k}-R_{b} P_{b k}\right|$

Total Congestion Cost Index (TCCI) of the transmission also can be formulated as follows,

$$
T C C I=\sqrt{\sum_{k \in B}\left(C C I_{k}\right)^{2}}
$$

where B is the set of all busses.

For multiple line congestion, the TCCI can be calculated in a similar manner to the single line congestion case. However, it is necessary to know the contribution of congestion of a particular line to the TCCI. It is difficult to calculate the CCI for congestion of each line due to the non linearity of power system.

Therefore, an approximate method is proposed to calculate the contribution of line congestion to the TCCI. It is assumed that the CCI for single line congestion is proportional to its contribution to the TCCI resulting from the multiple line congestion.

\section{N. Congestion Cost-Definition [2]}

Congestion cost of a line is defined as the opportunity cost of transmitting power through it.

$C C_{i}=\left(\operatorname{lmp} p_{i 2}-\operatorname{lm} p_{i 1}\right) P_{i_{1} i_{2}}$

Where $\mathrm{CC}_{\mathrm{i}}$ is the congestion cost of line $\mathrm{i}$ in $\$ / \mathrm{hr}, \operatorname{lmp} p_{i 1}$, and $\operatorname{lmp}_{i 2}$ are LMPs of end buses of line $\mathrm{i}$ in $\$ / \mathrm{MWh}$, and $P_{i_{1} i_{2}}$ is power of line $i$ from bus $i_{1}$ to bus $i_{2}$ in MW. Total congestion cost of the network is equal to

$C C=\sum C C_{i}$

As more transmission lines are congested, i.e., as constraints for dispatching the cheapest undispatched generations increase, LMP differences among buses and consequently congestion cost increase. Therefore, congestion cost is a proper criterion for measuring price discrimination and consumer constraints. Consequently, congestion cost is a proper criterion for measuring the degree of competitiveness of an electric market.

\section{O. Consumer Total Payment [2]}

From the viewpoint of consumers, total payment for the electric power, i.e., total congestion cost plus total payment to generators, is important and hence it can be used as the criterion for transmission planning. The criterion, however, does not consider the competition.

\section{P. Flatness of price profile [2]}

In nodal pricing all participants purchase and sell electric energy at the LMP of their buses. In order to provide a competitive environment for all participants to purchase and sell energy at the same price, nodal prices must be made equal. In odder words, price profile must become flat. As the price profile becomes flatter, difference among LMPs decrease. Therefore, customers purchase and sell energy at less discriminative prices and consequently competition is encouraged.

\section{Q. Lerner Index [7]}

Lerner Index has been used as a measure of competitiveness in electricity market. Lerner Index is defined as (23).

$L I=\frac{\left(P^{m}-P^{c}\right)}{P^{m}}$

Where, $P^{m}$ is the market price and $P^{c}$ is the estimated competitive price. In competitive markets, usually, $\mathrm{P}^{\mathrm{m}}$ is the average of the electricity price over a specific region and $P^{c}$ is the estimated competitive price based on the estimation of the marginal cost of generators.

\section{R. Quantity Weighted Lerner Index [7]}

Quantity Weighted Lerner Index is defined as (24).

$Q L I=\frac{\sum_{t=1}^{T}\left(P_{t}^{m}-P_{t}^{c}\right) \times q_{t}}{\sum_{t=1}^{T} P_{t}^{m} \times q_{t}}$

Where, $\mathrm{q}_{t}$ is the total demand in the region and $\mathrm{T}$ is the duration of the study (other parameters are defined as section Q). This index has been calculated for New England Electricity market in [20], for California Electricity Market in [19].

\section{S. Modified Lerner Index [7]}

Modified Lerner Index is defined as section $\mathrm{S}$ but in the calculation of competitive benchmark prices the effects of transmission system has been considered. Other studies like [17], [18] has not considered the effect of transmission system on their competitive benchmark price calculation.

\section{T. Residual Supply Index (RSI) [40]}

For a given level of demand D the residual supply index (RSI) for firm $i$, is defined as (25).

$R S I_{i}=\frac{\left(\sum_{k=1}^{n} q_{k}\right)-q_{i}}{D}$

Where, $q_{k}$ is the total capacity of firm $k$. when RSI greater than 100 percent, suppliers other than firm $i$ have enough capacity to meet the demand of the market, and firm $i$ has less influence 
on the market. On the other hand if the RSI is lower than 100 percent, firm $i$ is a pivotal player in the market.

\section{U. Herfindahl-Hirschman Index (HHI) [40]}

The HHI is the sum of the squares of the market shares in the percentage. It is a statistical index that is often used to measure the degree of ownership concentration among suppliers in a relevant market. This index can measure the static generation capacity concentration very well.

\section{System Dynamic Herfindahl-Hirschman Index [10]}

The system dynamic index is energy based and takes transmission congestion into the consideration. This index can evaluate two components of the market power, namely, generation concentration and transmission congestion in one index.

It is based on the partitioning of the system into groups of similar prices and then calculating the group HHI based on the following formulation

$$
H H I_{G}=\sum_{i=1}^{m}\left(\frac{M W h_{i}}{\text { Total }_{G}} \times 100\right)^{2}
$$

Where $\mathrm{m}$ is the total number of groups in the whole system and $\frac{M W h_{i}}{\text { Total }_{G}}$ is the share of each generator in one specific group from the total generation of that group.

Finally, system HHI is defined as the square root of weighted average group HHI based on the generation shares in percentage for all groups.

$$
H H I_{S}=\sqrt{\sum_{j=1}^{n}\left(\frac{M W h_{j}}{\text { Total }_{S}} \times H H I^{2}{ }_{G j}\right)}
$$

In this criterion, the number of groups is a measure of the market power due to congestion and the $\mathrm{HHI}_{\mathrm{S}}$ is the measure of the market power because of generation concentration.

\section{W. National Electricity Market (NEM) - Australia [8]}

The Australian National Electricity Market (NEM) is built on an interconnected, multistate power system with total length of around $4000 \mathrm{~km}$ and relatively small demand of 30GW [35]. The national Electricity Market Management Company (NEMMCO) is market and power system operator and planning manager.

The Statement Of Opportunities (SOO) report and the Annual National Transmission Statement (ANTS) report along with the more detailed planning report produced by each Regulated Transmission Network Service Providers (RTNSP), provide a basis for the expansion planning of the transmission system. The regulated transmission network providers undertake the transmission planning within their territories according to a "regulatory test" provided by the Australian Energy Regulator (AER) as a part of Australian Competition and Consumer Commission (ACCC).
The economic performance measurement part is a "Cost Benefit Test", which must identify the best option, with a positive net benefit under most scenarios of future market development.

Because of the practical difficulties in implementing this test, currently it is not accommodated in the planning algorithms of the regulated transmission network service providers.

Moreover, AER has recently [21], [22] introduced the following metrics for measuring of congestion impact on NEM. These indices are useful for economic evaluation of the transmission network:

\section{P.1 Total Cost of Constraint (TCC)}

TCC is defined as the difference between the dispatch cost, equation 1, with and without transmission constraint. Mathematical formulation of TCC is detailed in section A.

\section{P.2 Outage Cost of Constraint (OCC)}

OCC is defined as the difference of the dispatch cost between two cases; (a) without transmission lines due to outages (planned or unplanned) and (b) with transmission lines due to outages when their constraints are removed.

\section{P.3 Marginal Cost of Constraints (MCC)}

The MCC is derived by summing up the marginal constraint values reported with every constraint for every five minute dispatch interval over the year to obtain a Cumulative Marginal Value (CMV).

\section{California Electricity Market - Transmission Economic Assessment Methodology (TEAM) [36] [37]}

Transmission Economic Assessment Methodology (TEAM) introduced by the California Electricity Market does not consider the load elasticity. A predefined Value of Lost Load has been considered as the highest value of electricity for all consumers in the system.

TEAM proposes two alternatives for economic evaluation of the transmission expansion or upgrade projects.

The first methodology is through measuring of the social benefit of transmission expansion or upgrade project. This approach has been detailed in section A.

The second measure is called Modified Societal Test. In modified societal test measure, Monopoly Rent (Mrent) is defined as the excess surplus of producers because of strategic biding. This test excludes producers' monopoly rent in the surplus calculation and change in monopoly rent in benefit calculation.

$\Delta T S^{\prime}=\Delta T S-\Delta$ Mrent

In modified societal test by giving the same weight to the monopoly rent as the other market participants, transmission expansion or upgrade projects will be selected not only based on the maximisation of total surplus but also minimisation of the monopoly rent. 


\section{Y. New York Electricity Market [38]}

To suit various needs for viewing the impact of congestion, four congestion metrics were developed by New York ISO.

\section{Z.1 Change in Production Cost}

This metric has the same definition of section P.1.

\section{Z.2 Change in Congestion Payments}

Change in congestion payment is defined as the difference between congestion payment of loads, the sum of the locational marginal price congestion component times the load affected, with and without transmission constraints.

\section{Z.3 Change in Payments to Generators}

The difference between the payments to generators in cases of with and without transmission constraints is defined as the change in payments to generators.

\section{Z.4 Change in Load Payments}

The difference between the load payment in cases of with and without transmission constraints is defined as the change in load payments.

\section{Z. New England Electricity Market [39]}

New England electricity market has introduced a set of indices for the evaluation of its electricity markets. With some changes these indices can be used for evaluation or final check up, ancillary indices, of transmission expansion or upgrade projects.

\section{AA1. Herfindahl-Hirschman Index for the System and Specific} Areas

HHI definition in New England Electricity market is the some as it was detailed in section $\mathrm{V}$.

\section{AA2. Market Share by Participant Bidder}

The generation capability for the lead participants with the largest portfolios during one year can be a measure of concentration in the market.

\section{AA3. Forward Contracting}

Estimates of the level of forward contracting and self-supply generation in an electricity market are important in evaluating how well the electricity market is working. Forward contracting not only insulates load from short-term price volatility, it also serves as an incentive for generators to offer generation at marginal cost. Level of forward contracting has a close relationship with a successful transmission expansion planning.

\section{AA4. Residual Supply Index}

Mathematical calculation of RSI is the same as definition in section U, but New England electricity market only considers the largest seller's supply in its calculation.

\section{AA5. Competitive Benchmark Analysis}

The definition of this measure is the same as section $\mathrm{S}$.
AA6. Implied Heat Rates

This index might be used as an ancillary index for final check up of the transmission projects. The market prices for electricity and fuel are used by the New England Electricity market to derive the heat rate of various tapes of generators. If the price of a fuel rises at a rate more than that of electricity, even generators with high thermal efficiency may not be able to recover fuel costs or to earn additional revenues while producing the electricity. A successful long-term transmission planning can play as an issuance for lowering the price of electricity and keeping the efficient generators in the market.

\section{AA7. Net Revenues and Market Entry}

New England electricity market compares market revenues with the revenue requirements for a new generating unit seeking to enter the market. A successful transmission planning can help to distribute the generators uniformly over the transmission system and raises the competitiveness in the market. This index can be used as an ancillary index.

\section{AA. Pennsylvania, New jersey, and Maryland Electricity Market (PJM) [6] [4]}

Planning the enhancement and expansion of transmission capability on a regional basis is one of the primary functions of regional transmission organizations. PJM implements this function through the Regional Transmission Expansion Planning (RTEP) process described in Schedule 6 of the PJM Operating Agreement [6].

PJM's RTEP process includes an economic planning component. It is designed to develop cost-effective solutions to alleviate congestion on the transmission system. The PJM Economic Planning Process still is under development as part of market-efficiency initiatives and is evolving through an extensive stakeholder process [4].

Tables 1 and 2 summarises the economic measures introduced through this article.

Table 1 Summary of economic assessment metrics for transmission expansion or upgrade projects (Main Indices)

\begin{tabular}{|c|c|c|c|}
\hline \multirow{2}{*}{ Metric } & \multicolumn{3}{|c|}{$\begin{array}{r}\text { Electricity Market Key } \\
\text { Characteristics }\end{array}$} \\
\cline { 2 - 5 } & $\begin{array}{r}\text { Efficie } \\
\text { ncy }\end{array}$ & $\begin{array}{c}\text { Comp } \\
\text { etitive } \\
\text { ness }\end{array}$ & $\begin{array}{c}\text { Customer } \\
\text { choice }\end{array}$ \\
\hline \hline Aggregated Surplus & $\sqrt{ }$ & $\times$ & $\times$ \\
\hline Efficiency Loss & $\sqrt{ }$ & $\times$ & $\times$ \\
\hline Congestion Revenue & $\sqrt{ }$ & $\times$ & $\times$ \\
\hline Producers' Surplus & $\sqrt{ }$ & $\times$ & $\times$ \\
\hline
\end{tabular}




\begin{tabular}{|c|c|c|c|}
\hline Consumers' Surplus & $\sqrt{ }$ & $x$ & $x$ \\
\hline Individual Producer Surplus & $\sqrt{ }$ & $x$ & $x$ \\
\hline Individual Consumer Surplus & $\sqrt{ }$ & $x$ & $x$ \\
\hline Nodal Producer Surplus & $\sqrt{ }$ & $x$ & $x$ \\
\hline Nodal Consumer Surplus & $\sqrt{ }$ & $x$ & $x$ \\
\hline Redispatch Power & $\sqrt{ }$ & $x$ & $x$ \\
\hline Redispatch Cost & $\sqrt{ }$ & $x$ & $x$ \\
\hline Total Congestion Cost [1] & $\sqrt{ }$ & $x$ & $x$ \\
\hline Congestion Cost [2] & $\sqrt{ }$ & $x$ & $x$ \\
\hline Cost-Benefit Test & $\sqrt{ }$ & $x$ & $x$ \\
\hline Outage Cost of Constraint & $\sqrt{ }$ & $x$ & $x$ \\
\hline Marginal Cost of Constraint & $\sqrt{ }$ & $x$ & $x$ \\
\hline Change in Payments to Generators & $\sqrt{ }$ & $x$ & $x$ \\
\hline Change in Load Payments & $\sqrt{ }$ & $x$ & $x$ \\
\hline Flatness of price profile [2] & $x$ & $\sqrt{ }$ & $x$ \\
\hline Lerner Index [7] & $\times$ & $\sqrt{ }$ & $x$ \\
\hline Quantity Weighted Lerner Index [7] & $x$ & $\sqrt{ }$ & $x$ \\
\hline Modified Lerner Index [7] & $x$ & $\sqrt{ }$ & $x$ \\
\hline Residual Supply Index (RSI) & $x$ & $\sqrt{ }$ & $x$ \\
\hline$H H I$ & $x$ & $\sqrt{ }$ & $x$ \\
\hline System Dynamic HHI & $x$ & $\sqrt{ }$ & $x$ \\
\hline Modified Societal Test & $\sqrt{ }$ & $\sqrt{ }$ & $\times$ \\
\hline
\end{tabular}

Table 2 Summary of economic assessment metrics for transmission expansion or upgrade projects (Ancillary Indices)

\begin{tabular}{|c|c|}
\hline Metric & Description \\
\hline \hline Market Share by Participant Bidder & AA.2 \\
\hline Forward Contracting & AA.3 \\
\hline Implied Heat Rates & AA.6 \\
\hline Net Revenues and Market Entry & AA.7 \\
\hline
\end{tabular}

Since firstly, the analysis of the all introduced metrics can not be accommodated in a single paper and secondly, some of introduced indices have the same nature, a group of representative indices has been selected. Economic assessment of a gradual transmission upgrade pattern has been calculated by selected metrics. A typical 6-bus transmission system has been used in the aforementioned analysis. Section $\mathrm{V}$ will present a critical analysis on selected measures.

\section{ECONOMIC PERFORMANCE METRICS IN THE TRANSMISSION INVESTMENT PROBLEM - A CRITICAL ANALYSIS}

V.1 Modified Wood and Wollenberg 6-bus case study[16] The single line diagram of Modified Wood and Wollenberg 6bus case study has been shown in figure 1 . The system has three generators with total capacity of $580 \mathrm{MW}$ installed at buses 1,2 , and 3 . Three loads with total demand of 570MW, $190 \mathrm{MW}$ each, have been connected to buses 4,5 , and 6 . Initial total transmission capacity is $570 \mathrm{MW}$ which will be upgraded consequentially by $20 \mathrm{MW}$ steps according to pattern shown in figure 2. The gradual upgrade of transmission system is based on the congestion revenue of each transmission line. The line with the highest congestion revenue is chosen for $20 \mathrm{MW}$ upgrade of capacity.

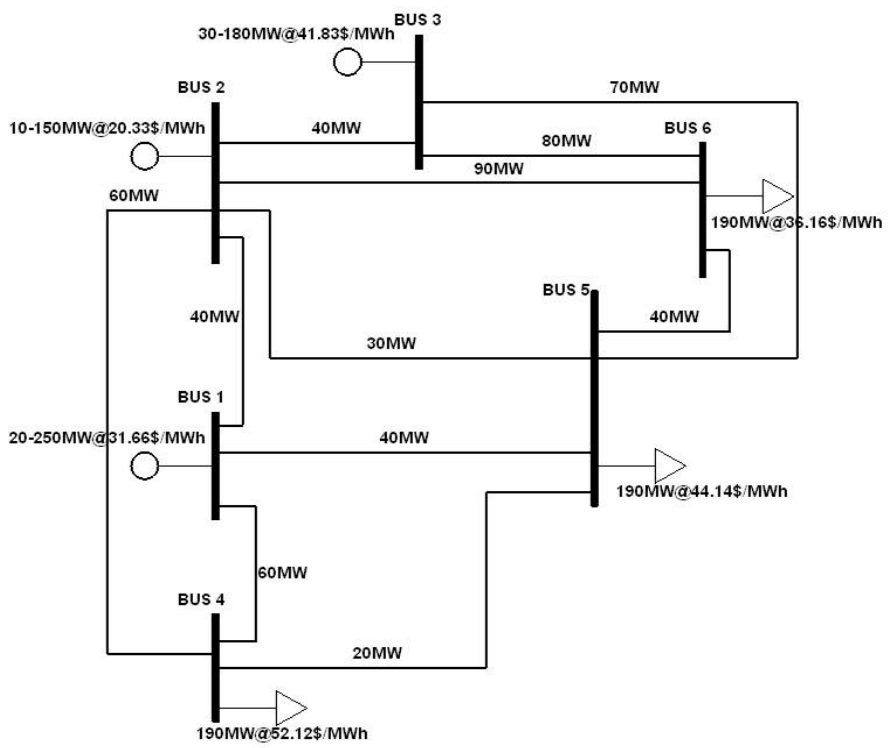

Figure 1 Single line diagram of modified Wood and Wollenberg 6-bus test system [ww]

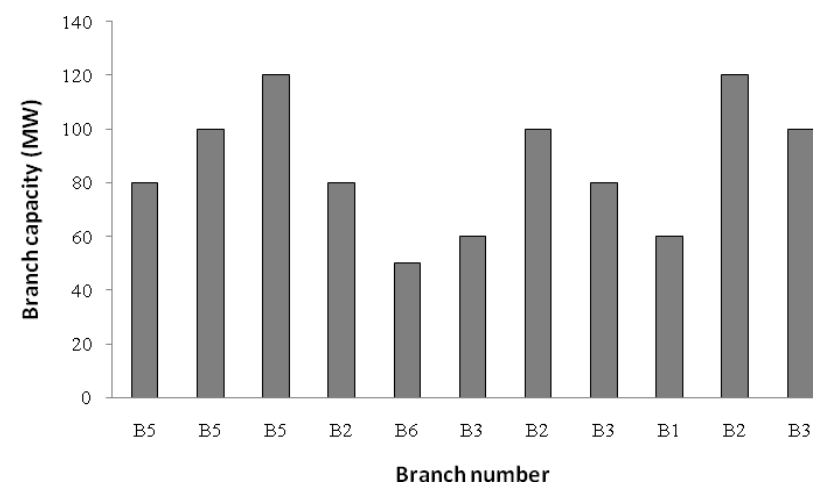

Figure 2 Gradual upgrade pattern of transmission system capacity by $20 \mathrm{MW}$ steps

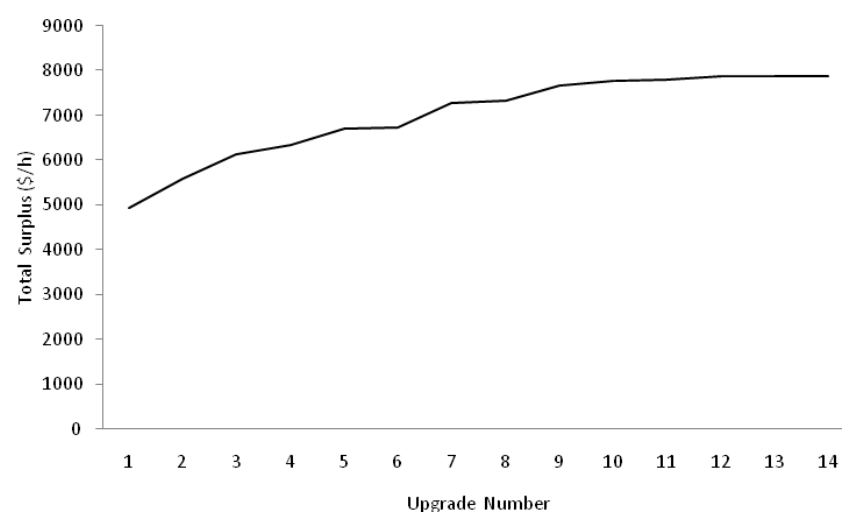

Figure 3 Total surplus in $\$ / h$ vs. different scenarios of upgrading 


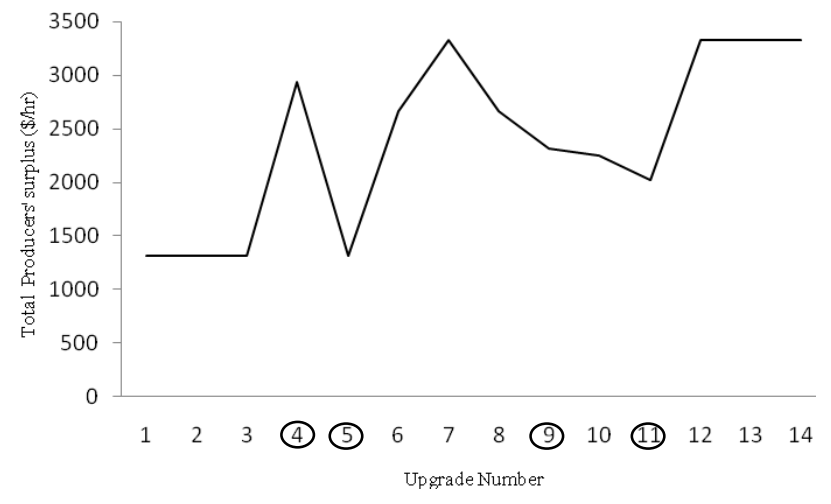

Figure 4 Total producers' surplus in $\$ / \mathrm{h}$ vs. different scenarios of upgrading

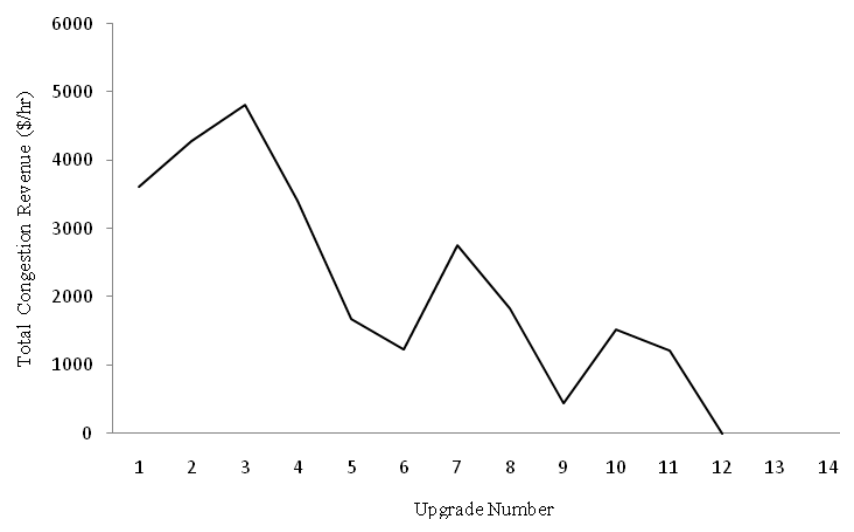

Figure 5 Total congestion revenue in $\$ / \mathrm{h}$ vs. different scenarios of upgrading

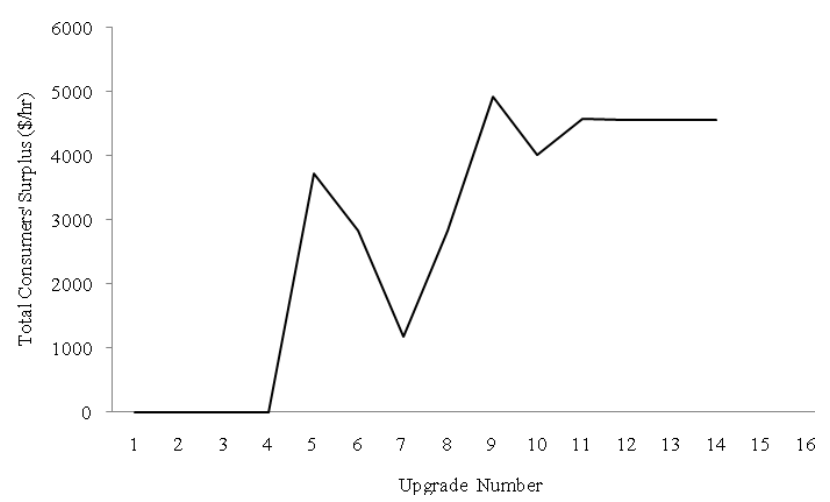

Figure 6 Total consumers' surplus in $\$ / \mathrm{h}$ vs. different scenarios of upgrading

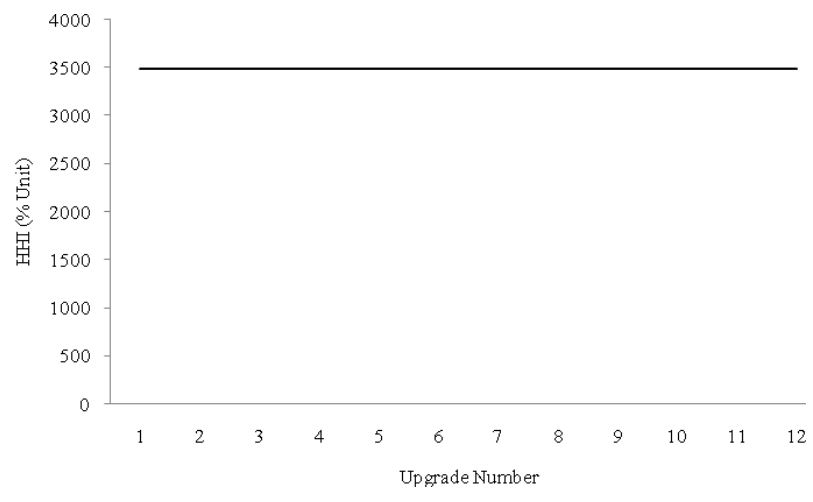

Figure $7 \mathrm{HHI}$ index in percent unit vs. different scenarios of upgrading

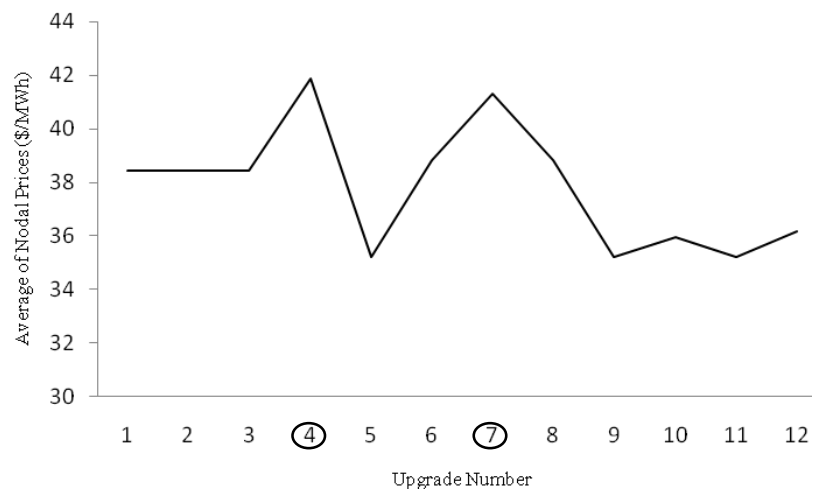

Figure 8 Average of nodal prices in $\$ / M W h$ vs. different scenarios of upgrading

As in figure 3, the upgrade pattern has caused a steady increase in total surplus of the system.

An important feature is that the total surplus has an asymptotic behaviour. Total surplus without transmission constraints is the asymptote of this curve. Therefore the change in total surplus as a result of transmission capacity upgrade is bounded. Such a characteristic can be seen in producers' surplus, consumers' surplus and congestion revenue of the system too. Asymptotic phenomenon is due to supply and demand functions and trading area in economy.

Another feature which can be drawn by comparing figure 3 with figure 4,5 , and 6 is the conflicting pattern among the total system surplus, producers' surplus, consumers' surplus, and congestion revenue of the system. For example, upgrade 5 will be assessed based on the total surplus and total consumers' surplus a positive one while this upgrade will not be accepted based on the total producers' surplus and congestion revenue. This conflicting pattern can be seen frequently through our upgrade pattern, such as upgrade 4,9 and 11.

Regarding competitiveness indices, as $\mathrm{HHI}$ in figure 7, all of them are static and do not consider the effects of transmission system in their calculation. System dynamic HHI index is one step in solving these shortcomings.

And finally nodal prices have been used as another signal for evaluation of transmission project. Transmission upgrade 4 and 7 are two typical upgrades for which the average for nodal prices is high which total surplus is improved. Regarding transmission upgrade 7, producers' surplus and congestion revenue are increased while the consumers' surplus is decreased.

Outage Cost of Constraint (OCC) introduced by Australian Energy Regulator could evaluate the contingency cost of transmission expansion or upgrade projects in monetary term. OCC can be used as an insurance cost for transmission upgrade or expansion projects.

Finally, ancillary indices introduced in table 2 can be used as the final check up for transmission expansion or upgrade 
projects. These indices would be very useful in exploring the impacts of transmission expansion as a structural change on other aspects of power system and electricity market.

Changing the view angle, the ultimate goals of restructuring in electricity market have been reported [15] as lower prices and higher quality of services in short term and improvement in economic efficiency, competitiveness, and consumer freedom of choice in long term. A closer look at table 1 reveals that first set of indices evaluate the transmission projects based on the economic efficiency, and the second set of indices based on the competitiveness level in electricity market. As in table 1 , no index has been found for explicit evaluation of transmission projects on customer freedom of choice.

Based on the above analytical review, figure 8 depicts the proposed framework for the economic assessment of transmission projects.

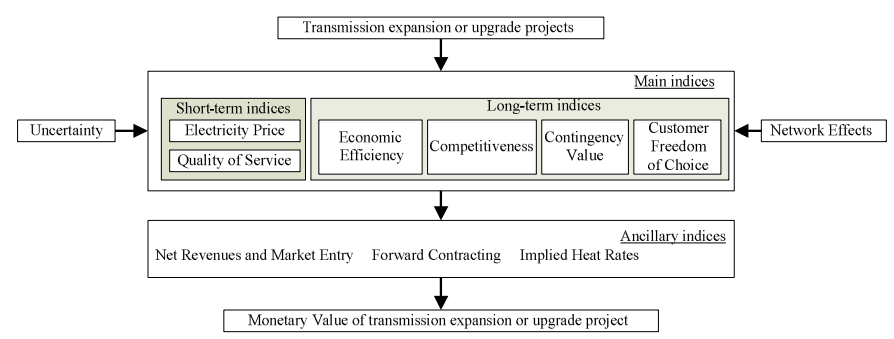

Figure 9 The proposed economic assessment framework for calculating the monetary value of transmission expansion or upgrade projects

According to figure 9, the proposed economic assessment framework has a two-step evaluation, namely, main and ancillary. Main evaluation can be carried out based on economic efficiency, competitiveness, (as reviewed in table 1 ), contingency value, and customer freedom of choice as long-term indices or electricity prices and quality services as short-term indices. Uncertainty and network effects must be considered in $\mathrm{t}$ monetary evaluation. Ancillary indices as tabulated in 2 could be used as the final check up of the transmission projects and/or comparing two transmission projects with the same monetary value based on the main indices. Net revenue and market entry and forward contracting are two examples of these indices.

\section{CONCLUSION REMARKS}

In this paper, we have presented a classified list of major metrics on economic assessment of transmission expansion or upgrade projects. The metrics have been classified as the main and ancillary measures. Main measures try to evaluate the transmission projects based on the economic efficiency and competitiveness of the electricity market. Also, ancillary measures consider the effects of the transmission projects on other aspects of the electricity market and power system. Ancillary measures would be useful for final check up of transmission projects. An analysis has been done by applying a group of the reviewed indices on a typical 6-bus transmission system. Based on the reviewed indices and considering the experiences of the California, New England,
PJM, and NEM electricity markets a framework has been proposed for economic assessment of transmission projects. The proposed framework considers both main and ancillary metrics. Also, as two necessary parts, transmission network effects and uncertainties have been included in the flow of the proposed framework.

\section{REFERENCES}

[1] K. Y. Lee, S. Manuspiya, M. Choi, M. Shin, "Network Congestion Assessment for Short Term Transmission Planning under Deregulated Environment," IEEE 2001.

[2] M. O. Buygi, G. Balzer, H. Shanechi, M. Shahidehpour, "Market-based transmission expansion planning ," IEEE Trans. On power systems, vol.19, no. 4, November 2004.

[3] H. R. Outhred, "A review of experience with commercializing and regulating network services in the Australian electricity industry", Int. Energy J.,vol.6,no.1,pt.4,pp.4-99-4-108,June 2004.

[4] [Online] Available at http://www.pjm.com/planning/epis.html

[5] Working paper on, "Standardized transmission service and wholesale electric market design," Federal Energy Regulatory Commission, Washington, D.C, 2002.

[6] [Online] Available at http://www.pjm.com/documents/downloads/agreements/oa.pdf

[7] C. Cagigas, M. Madrigal, "Centralized vs. competitive transmission expansion planning: the need for new tools," 2003 IEEE

[8] R. J. Thomas, J. T. Whitehead, H. Outhred, and T. D. Mount, "Transmission system planning-the old word meets the new," in Proc. Of the IEEE, Vol. 93, No. 11, November 2005.

[9] R. Cagigas, M. Madrigal, "Centralized vs. competitive transmission expansion planning: the need for new tools," in Proc. 1991 IEEE Power Engineering Society Transmission and Distribution Conf., pp. 315-320.

[10] J. Yang, G. Jordan, "System Dynamic Index for Market Power Mitigation in the Restructuring Electricity Industry," IEEE 2000

[11] R. Allan, R. Billinton, "Probabilistic Assessment of Power Systems," Proceedings of the IEEE, Vol.88, No.2, February 2000

[12] R. Billinton, "Reliability Evaluation of Electric Power Systems," Tutorial presented at the Curtin University of Technology in Australasian Power Engineering Conference, 2007.

[13] C. A. Berry, B. F. Hobbs, W. A. Meroney, R. P. O’Neil, and W. R. Stewart, "Analyzing strategic behaviour in transmission networks," in IEEE Power Engineering Society Winter Meeting, New York, 1999.

[14] B. F. Hobbs, C. B. Metzler, and J. S. Pang, "Strategic gaming analysis for electric power systems: An MPEC approach," IEEE Trans. Power Syst., Vol.15, pp.638-645,May2000.

[15] F. Scheweppe, M. Caramanis, R. Tabors, and R. Bohn, Spot Pricing of Electricty. Boston, MA: Kluwer, 1988.

[16] A. J. Wood and B. F. Wollenberg, Power Generation Operation and Control, second edition, John wiley and Sons.

[17] J. Bushnell, C. Saravia, "An Empirical Assessment of the Competitiveness of the New England Electricity Market," Center for the Study of Energy Markets, University of California

[18] S. Borenstein, J. Bushnell, and C. R. Knittel, "Market Power in Electricity Markets: Beyond Concentration Measures," Center for the Study of Energy Markets, University of California

[19] Annual report on "Market issues and performance," Department of Market Monitoring California Independent System Operator

[20] “2006 Annual Markets Report”, New England ISO.

[21] "Indicators of the market impact of transmission congestion, Decision 9 June 2006," Australian Energy Regulator report

[22] "Indicators of the market impact of transmission congestion-report for 2006-07,” Australian Energy Regulator

[23] G. Latorre, R. D. Cruz, J. M. Areiza, and A. Villegss, "Classification of publication and models on transmission expansion planning," IEEE Trans. On power systems, vol.18, No. 2, May 2003

[24] A. K. David, F. Wen, "Transmission planning investment under competitive electricity market environment," 2001 IEEE

[25] J.P. Buechler, " Transmission planning in a market based environment," 2005 IEEE power engineering society general meeting.

[26] D. Bajs, G. Majstrovic, M. Majstrovic, "Transmission investment in an open electricity market," proceeding of the $4^{\text {th }}$ IASTED international conference, ower and energy system, june 28-30, 2004, Greece 
[27] F. Zheng, F. Wen, F.F. Wue, "Transmission investment in deregulated market environment, a literature survey, part I ," proceeding of the IASTED international conference, energy and power systems, April 1820, 2005, Thailand.

[28] F. Zheng, F. Wen, F.F. Wue, "Transmission investment in deregulated market environment, a literature survey, part II ," proceeding of the IASTED international conference, energy and power systems, April 1820, 2005, Thailand.

[29] F. F. wue, F. L. Zheng, F. S. Wen, "Transmission investment and expansion planning in a restructured electricity market," Elsevier

[30] R. D. Christie, B. F. Wollenberg, J. Wangesteen, "Transmission management in deregulated environemnt," proceedings of the IEEE, Vol. 88, no.2, February 2000.

[31] G. Gross, "Transmission planning and investment in the competitive environemnet," PSERC seminar presentation.

[32] G. Gross, "Transmission Planning and Investment in the Competitive Environment," PowerTech 2005, St. Petersburg, Russia, June 26-30, 2005

[33] P. Caro-Ochoa, "Evaluation of transmission congestion impacts on electricity markets," master thesis, university of Illinois

[34] G. B. Shrestha, P.A.J. Forseka, "Congestion-driven transmission expansion in competitive power markets,"IEEE trans. On power systems, vol.19, no.3, August 2004.

[35] "State of the energy market 2007," A report published by the Australian Energy Regulator

[36] "Transmission economic assessment methodology (TEAM)," California independent system operator, June 2004

[37] " Annual report on market issues and performance," Department of market monitoring, California Independent System Operator

[38] "Congestion cost metrics", New York electricity market

[39] “2006 Annual Markets Reports,” ISO New England Inc., June 11, 2007.

[40] A. R. Rahimi, A. Y. Sheffrin, "Effective market monitoring in deregulated electricty markets," IEEE trans. On power systems, vol. 18, no.2, may 2003

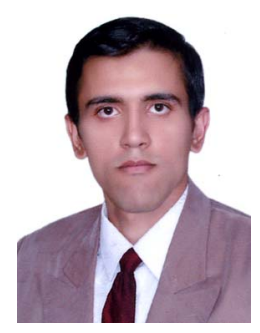

Mohammad R. Hesamzadeh (GSM'08) is with CQ University, Australia, as a Senior Researcher. His special fields of interest include high voltage transmission system design and planning, distribution and rural system studies, electricity market analysis, intelligent system applications in power systems and high voltage engineering. He is a Graduate Student Member of IEEE, Vice Chair of IEEE, Queensland Power Engineering Society, and a Professional Engineer in Australia.

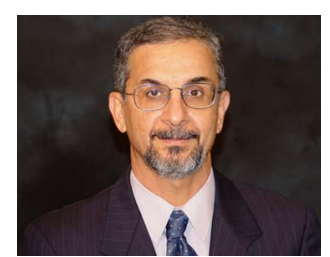

Nasser Hosseinzadeh (M'86) is currently the Head of Department of Systems at the Faculty of Sciences, Engineering and Health at Central Queensland University, Australia. He graduated from Shiraz University, Iran, in 1986 with a B.Sc. degree in electrical and electronics engineering. He worked in a research centre for five years before starting his postgraduate studies. He received a M.Sc. degree from Iran University of Science and Technology in 1992 and a Ph.D. degree from Victoria University in Australia in 1998. His special fields of interest include power system analysis and planning, power system stability, intelligent system applications in engineering, distribution networks and rural energy supply.

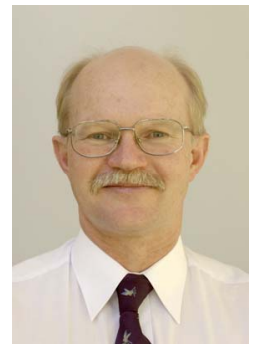

Peter J. Wolfs (M'80-SM'99) was born in Rockhampton Australia in 1959. He graduated from the Capricornia Institute of Advanced Education in 1980 with a B.Eng. degree. He subsequently obtained the M.Eng. degree from the Philips International Institute in the Netherlands in 1981 and the $\mathrm{Ph} . \mathrm{D}$. degree at the University of Queensland in 1992. He is the Associate Dean (Research and Innovation) at the Faculty of Sciences, Engineering and Health at Central Queensland University. His special fields of interest include rural and renewable energy supply, solar and hybrid electric vehicles and intelligent systems applications in railways. Professor Wolfs is a Fellow of Engineers Australia, a Registered Professional Engineer in the State of Queensland and a member of the Railway Technical Society of Australia. 